\title{
Е.С. Левицкая
}

\section{МЕХАНИЗМЫ ФОРМИРОВАНИЯ ФИБРОЗА ПОЧЕК С УЧЕТОМ МИКРОСОСУДИСТОГО ПОРАЖЕНИЯ}

\author{
Ростовский государственный медицинский университет, \\ Россия, 344022, Ростов-на-Дону, пер. Нахичеванский, 29. E-mail: es.med@mail.ru
}

Обзор посвящен описанию механизмов, участвующих в формировании фиброза почек. Представлены молекулярные факторы активации патологического процесса, сигнальных путей, компетентные клетки с синтезированием провосполительных медиаторов, роль эпителиально-мезенхимального перехода в развитии и прогрессировании фиброза почек. Продемонстрированы данные, свидетельствующие о значимости ремоделирования почечных артерий малого диаметра в развитии и прогрессировании фиброза почечной ткани. В качестве источников информации для полного раскрытия темы обзорной статьи с представлением современных взглядов на изучение данной проблемы, использованы базы цитирований PubMed, РИНЦ, Scopus, Web of Science, Google Scholar, Index Copernicus, Ulrich’s Periodicals Directory.

Ключевые слова: обзор, фиброз почек, артерии малого диаметра, сигнальные пути, провоспалительные медиаторы.

\section{E.S. Levitskaya}

\section{MECHANISMS OF FORMATION OF KIDNEY FIBROSIS BASED ON MICROVASCULAR LESIONS}

\author{
Rostov State Medical University, \\ 29 Nakhichevanskiy st., Rostov-on-Don, 344022 Russia. E-mail: es.med@mail.ru
}

The review deals with the description of the mechanisms involved in the formation of kidney fibrosis. Presented molecular factors activation of the pathological process, signaling pathways, competent cells with synthetic provospolitelnyh mediators, the role of epithelial-mesenchymal transition in the development and progression of renal fibrosis. Demonstrated evidence of the importance of the remodeling of the renal arteries of small diameter in the development and progression of renal fibrosis tissue. Sources of information on topics Review article full disclosure, a presentation of the current views on the study of this problem, use the database PubMed citations, RISC, Scopus, Web-Mathematical Sciences, Google Scholar, Copernicus index, Ulrich Periodicals Directory.

Keywords: renal fibrosis, small-diameter arteries, signaling pathways, proinflammatory mediators. 


\section{Введение}

$\mathrm{O}$ сложнение болезней почек хронической почечной недостаточностью (ХПН) ассоциировано с ростом смертности и инвалидности населения, включая лиц молодого трудоспособного возраста [1]. Темпы развития ХПН зависят от многих причин, но, прежде всего, необходимо отметить своевременность диагностики и эффективное лечение основного заболевания. Достижение терминальной ХПН требует диализной терапии и трансплантации почек, что значительно снижает качество жизни и затраты на лечение таких больных. Понимание патогенетических процессов, происходящих при ХПН, позволяет проводить адекватную терапию, направленную на замедление ремоделирования почек, а также выполнять диагностический поиск, уточняющий тяжесть повреждения почечной ткани.

Фиброз интерстициальной ткани является основным механизмом развития ХПН, а также предиктором, определяющим прогноз больных с различными нефропатиями [2]. Процесс фиброгенеза сложен, а развитие его зависит от многих компонентов, характеризующихся одновременным, параллельным развитием или потенцирующим действием для инициации других факторов патогенеза. Интерстициальный фиброз почки может быть определен как избыточное накопление коллагена и подобных ему веществ в интерстиции [3]. Следует отметить, что физиологической нормой является наличие коллагена Iи III типов в почечной ткани, функцией которых является создание строительного «каркаса» ткани почек [4]. Существуют различные причины развития фиброгенеза, влияющие на функциональную полноценность почки. При заболеваниях, характеризующихся ограниченными патологическими процессами в ткани почек, развития фиброза является локальным, преимущественно не снижающим или частично снижающим почечную функцию. Формирование процессов фиброзирования в таких ситуациях является защитной реакцией организма, с целью ограничения патологического очага, а также нормальной ответной реакцией на протекающие воспаление и повреждение почек. Другими изменениями почечной ткани является диффузный характер фиброзного ремоделирования, вследствие персистирующего действия повреждающего фактора на интерстициальную и гломерулярную ткань почек, приобретающий генерализованный характер. Вторая модель почечного повреждения приводит к функциональной потере структур почек разной степени выраженности, зависящей от силы и длительности действия агрессивного фактора, своевременной диагностики и медикаментозного контроля патогенетических процессов. Конечным этапом является развитие ХПН и смерти больного. Наиболее частыми причинами диффузной фиброзной перестройки ткани почек являются гломерулонефриты, сахарный диабет, ишемическое и гипертонической повреждение почек, а также лекарственная и токсическая агрессия [5].

По мнению ряда авторов, механизм формирования фиброза почек можно условно разделить на 4 части: фаза травмы и активации клеточных механизмов, фаза активации сигнальных путей фиброгенеза (фаза сигнализации), фаза реализации процессов фиброгенеза (фаза исполнения) и деструктивная фаза или прогрессирования [6].Некоторые исследователи выделяют только 3 основные фазы патогенеза фиброза почек: индукция воспаления, воспалительный матричный синтез, поствоспалительный матричный синтез [7]. Предложенные классификации взаимно дополняют друг друга и отражают единые процессы этапов фиброобразования. Продолжительность каждой фазы индивидуальна и зависит от силы фактора агрессии и их количества, а также преморбидного фона. Зачастую фазы фиброза почек могут протекать одновременно, с последующим развитием органного ремоделирования и снижением функции почек.Важно отметить, что начальное действие фактора агрессии на почечную ткань приводит к запуску сигнальных путей активации биологически активных веществ, повреждающих почечную ткань, а при окончании его влияния процессы фиброгенеза могут прогрессировать посредством компенсаторных (адаптационных) процессов в почках, а также гиперактивности функций патологических резидентных клеток почек и вновьобразованных веществ.

Одну из ключевых функций в реализации патологического фиброгенеза выполняют фибробласты и миофибробласты. С учетом измененных условий функционирования почек фибробласты могут приобретать миофибротический фенотип с повышенным синтезом, прежде всего, коллагена Iи III типа $[8,9,10]$. Более того, значительный вклад в образование коллагена I типа 1а (coll1a1)вносят мигрированные перициты в интерстициальную ткань почек и приобретающие также функцию миофибробластов. Так, по результатам экспериментальных исследований на крысах LinSL etal.были установлены, коллагенпродуцирующие клетки (фибробласты, перициты), в условиях развития фиброза почек, вызванным сосудистой травмой [8]. Данный процесс является одним из основных механизмов, приводящих к накоплению внеклеточного матрикса. Важно отметить, что прогрессирующий патологический процесс фиброобразования характеризуется накоплением не только внеклеточного матрикса, но и патологических белков, в норме не определяющихся в почечной ткани.

Определенная роль отводится инициированию воспалительных клеток, значение которых носит адаптационный, защитный характер при возникающем повреждении тубулоинтерстициальной ткани. Дисбаланс в системе лимфоцитов с активацией CD-4,CD-8 и уменьшением интелейкина 6 , повышают восприимчивость к действию медиаторов повреждения и обладают непосредственным агрессивным воздействием на почечную ткань $[11,12]$.

Принимающие участие макрофаги [13], дендритные $[14,15]$ и тучные [16] клетки занимают также важное место в каскаде нивелирования развития и прогрессирования фиброза почечной ткани, за счет выделения провоспалительных медиаторов, а также синтеза веществ, инициация которых происходит под воздействием биологически активных веществ указанных выше компетентных клеток воспаления.

Развитие этапов фиброза почки было детально показано в работе ZhaoJ. etal. на модели крыс [17]. Животным выполняли одностороннюю обструкцию мочеточника, с динамическим контролем состояния и процессов, происходящих в тубулоинтерстициальной ткани. Авторами показано, что в условиях оксидативного стресса происходит накопление активных форм 
кислорода и ядерного фактора каппа В с активацией ренин-ангиотензин-альдостероновой системы. Дальнейшим этапом является развитие механизмов регулирования преапоптотической трансдукции сигнала, с последующим формированием повышения апоптоза клеток трубчатого эпителия. Параллельно с данными процессами происходит активация макрофагов и увеличение противовоспалительных медиаторов, замедляющих гибель и увеличивающих пролиферацию клеток. Сочетание данных механизмов вызывает нарушение метаболизма, нормальных межклеточных взаимодействий и гемодинамические изменения, что приводит к потенцированию клеточного апоптоза и некроза, а также увеличению инфильтрации макрофагов, поврежденной ткани. Образованные фибробласты приобретают фенотип миофибробластов, с индукцией фибротической перестройки почечной ткани.

Важно отметить, что независимо от инициирующего фактора повреждения почек характерными признаками тубулоинтерстициальных заболеваний являются атрофия трубчатой зоны, интерстициальный фиброз и клеточная инфильтрация [18, 19]. Данные изменения почечной ткани можно рассматривать с позиции «почечного» континуума, конечным итогом которого является развитие терминальной почечной недостаточности и смерти больного.

Замещение нормального фенотипа клетки на патологический (не свойственный данному типу ткани) входит в понятие эпителиально-мезенхимального перехода (ЭМП), являющегося неотъемлемой частью развития и прогрессирования фиброза почек, вплоть до терминальной почечной недостаточности [20]. Основу ЭМП составляют инициация под действием дисбаланса про- и противовоспалительных медиаторов сигнальных путей, вызывающих развитие структурной перестройки клетки. Необходимо отметить, что неотъемлемой частью ЭМП является экспрессия генов под воздействием патологического стимула на почечную ткань [18]. Перечисленные факторы ЭМП обуславливают, прежде всего, избыточную секрецию цитокинов и повышенное образование рецепторов эффекторных тканей почек, реализующих их патологическое действие $[21,22]$.

Трансформирующий фактор роста бета (TGF- $\beta$ ) pacсматривается в качестве центрального посредника в реализации фиброза почек, за счет активации сигнального пути ЭМП $[23,24]$. TGF- $\beta$ рассматривается как профибротический цитокин, инициирующий и моделирующий патофизиологические процессы [25]. Биологическими свойствамиTGF- $\beta$ являются регуляция клеточной пролиферации, апоптоза, дифференцировки, миграции и дифференцировки клеток, а также TGF- $\beta$ приводит к модуляции синтеза белков внеклеточного матрикса[25]. Существует три основные изоформы цитокина TGF- $\beta$ (TGF- $\beta$ I, TGF- $\beta$ II, TGF- $\beta$ III), среди которых наибольшее биологическое и патологическое действие имеет TGF- $\beta$ I. При повреждении ткани почек различного генеза происходит гиперактивацияTGF- $\beta$ с помощью сигнальных путей, прежде всего, опосредованныхSmad и МАРК, с последующим патологическим проявлением своих функций.

Установлено значительное повышение экспрессии TGF- $\beta$ и рецепторов к ним на эффекторных органах при многих патологиях органов и систем, включая диабетическую нефропатию, IgA-нефропатию, фокальносегментарныйгломерулосклероз, волчаночный гломерулонефрит и другое [26]. Еще в 1997 году Murakami K etal показали повышениеTGF- $\beta$ в моче при различных заболеваниях

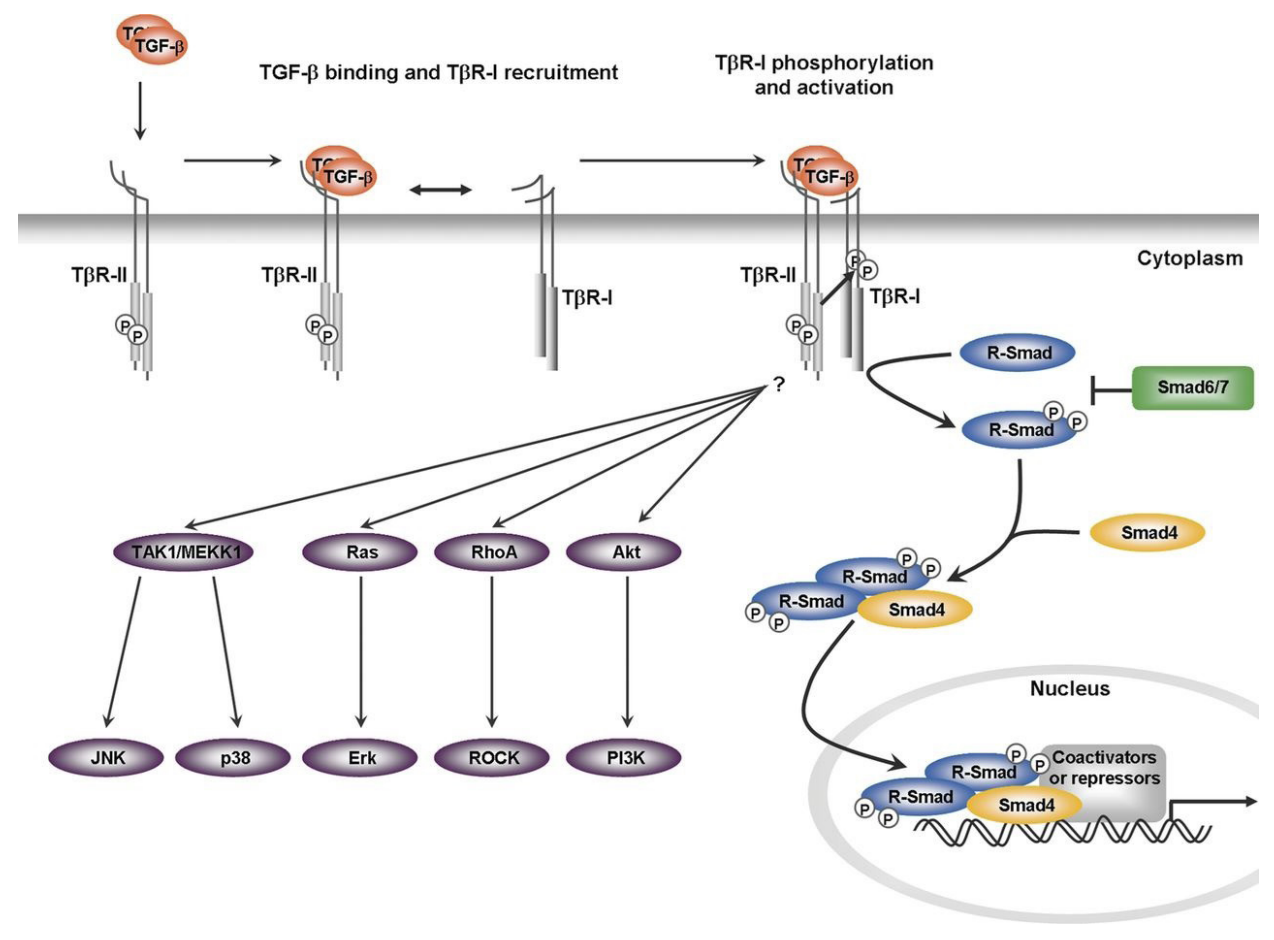

Рисунок 1. Пути реализации патологической экспрессии TGF- $\beta$ с помощью различных сигнальных путей

Figure 1. Ways to implement the pathological expression of TGF- $\beta$ by various signaling pathways [25] 
почек, отметив более выраженное его увеличение при прогрессировании фибротических процессов в почках. Проведенное исследование показало, что у пациентов сгломерулонефритом и протеинурией уровни TGF- $\beta$ значительно превышали данный показатель в группе здоровых людей и больных с гломерулонефритом и без протеинурии. Более того необходимо отметить, что научно-исследовательский поиск последних лет в области патогенетической значимости TGF- $\beta$ в развитии фиброза почек показал повышение экспрессии TGF- $\beta$ в подоцитах и прогрессирование наиболее социально-значимых почечных патологий - подоцитопатий [27].Авторы указывают, что экспрессия TGF- $\beta$ может обладать предикторной значимостью в прогнозе почечной выживаемости.

Значимость TGF- $\beta$ в фиброзировании почечной ткани при хронической патологии почек не вызывает сомнений и показана многими научными исследованиями. В то время как роль TGF- $\beta$ при формировании прогрессирующего повреждения почек при острых формах заболеваний остается предметом дискуссий и в настоящее время. В начале развития острого повреждения почек возникает патологическое повышение секреции TGF- $\beta$ для реализации дифференцировки поврежденных клеток, апоптоза эпителиальных клеток и отложения внутриклеточного матрикса. Высказано предположение о решающей роли в прогрессировании повреждения почечной ткани и дальнейшего формированием фиброза, вещества TGF- $\beta$, с последующей активацией сигнальных путей [28]. Экспериментальные данные показали, что при инактивации рецепторов к TGF- $\beta$ в проксимальных канальцах крыс, происходит снижение активности процесса и нивелирование патологических реакций [25].

Результаты исследований последних лет продемонстрировали значимость еще одного маркера почечного ремоделирования Notch $[29,30]$. Путь Notch представляет собой каскад молекулярных взаимодействий, выраженный от генетической экспрессии белков Notch активных веществ и рецепторного аппарата на эффекторных клетках почках. Установлено, что путь Notch реализуется посредством нескольких типов рецепторов, имеющих определенную биологическую значимость - рецепторы Notch (ReNotch) 1-4, наибольшую функциональную нагрузку среди которых имеют ReNotch 1 и 2 типов [31]. Физиологическая активность пути Notch обнаруживается в период эмбриогенеза, роль которого определяется нормальным созреванием структур почек [32]. Проведение научно-исследовательских работ показало, что после рождения активность Notch в физиологических условиях не определяется, а возрастает при патологических состояниях почек любой этиологии [33]. Конечным этапом в инициировании каскада Notch является формирование протеинурии, с последующим переходом в гломерулосклероз [34]. Важно отметить, что в период эмбриогенеза активность Notch не определяется в подоцитах, тогда как при развитии подоцитопатийреализация Notch значительно возрастает. Полученные в экспериментальных условиях подоцитопатии у крыс с патологической экспрессией Notch 1типа, позволили установить быстрое развитие протеинурии и гломерулосклероза, с летальным исходом животных через несколько недель [35]. Авторы отмечают, что после гиперактивации пути Notch происходило резкое ухудшение клинических и морфологических характеристик. Еще одним важным фактом в патогенетической значимости пути Notch является выявленная взаимосвязь с повышен- ной экспрессией TGF- $\beta$ [36]. Установлено в экспериментальных условиях в пробирке, а также на животных, что TGF- $\beta$ регулирует активность Notch по типу положительной связи. Исследователи предполагают, что детальное изучение активности и реализации Notch при нефропатиях, позволит определить диагностическую значимость в прогрессировании фиброзного ремоделирования почки, а также установить новые способы лечения и вторичной профилактики данных состояний.

Рассматривается роль новых, мало изученных, предикторов фиброза почек в развитии и прогрессирования патогенетического каскада патологического фиброобразования. Одним из таких инициаторов выступает повышенная активность сигнального пути белка сосудистой адгезии (VAP-1) [37]. VAP-1 представляет собой мембранный белок, регулирующий процесс лимфоцит-эндотелиоцитарного взаимодействия. Биологическая роль VAP-1 проявляется в виде ролинга, адгезии и диапедеза лимфоцитов через эндотелий сосудов [37]. Активизация сигнального пути VAP-1, приводит к потенцированию воспаления, с последующей индукцией тканевого фиброзного ремоделирования. Научно-исследовательский поиск целесообразности изучения и определения места в патогенетическом каскаде фиброзной перестройки почек активно проводится в настоящее время.

Необходимо представить данные, касающиеся роли микрососудистой перестройки в развитии и прогрессировании фиброза почек.

Иерархия сосудистого русла представляет собой точную, но сложно организованную сеть. Нарушение нормального строения сосудов любого уровня, врожденного или приобретенного характера, представляет, прежде всего, недостаточность зависимого органа. Длительность повреждения и гемодинамический дисбаланс, возникающий в сосудах, формируют адаптивноеи/или дезадаптивное ремоделирование органа, с развитием хронической недостаточности функции, а в последствии и полиорганной декомпенсации. Микрососудистое звено артериального русла выполняет ряд важных задач. Во-первых, артерии малого диаметра, разветвляясь на прекапилляры и капилляры, формируют доставку крови к ткани органа, для осуществления его метаболических потребностей. Во-вторых, позволяют адекватно поддерживать основную функцию органа, например, сохранение оптимальной скорости клубочковой фильтрации почек [38]. Среди причин, приводящих к ремоделированию сосудистой стенки, необходимо выделить механический фактор, возникающий вследствие постоянно повышенного системного артериального давления, фактор нейрогуморальной агрессии, фактор метаболических и токсических изменений[39].B 1999 году M. Mulvany была предложена классификация 6 типов структурной перестройки сосудистой стенки.Градация изменения структуры артерий основана на трех вариантах согласно изменению толщины сосудистой стенки (гипотрофный, гипертрофный и эвтрофный), а также уменьшению (ремоделирование внутрь - «inward») или увеличению просвета сосуда (ремоделирование наружу - «outward») [40].

Собственный научно-исследовательский опыт в области взаимосвязи ремоделирования артерий почек малого диаметра и структурной перестройки почечной ткани показал статистическую закономерность морфологических показателей [40]. В исследование были включены 30 пациентов с хроническими гломерулонефритами, которым 
выполнись биопсия почек с определением наличия и выраженности тубулоинтерстициальной перестройки, а также вазометриямеждольковой артерии.По результатам проведенного исследования установлено наличие прямопропорциональной корреляционной зависимости между структурной перестройкой стенки междольковой артерии и величиной артериального давления, а также выраженности тубулоинтерстициального воспаления[40]. Показана связь между уменьшением просвета междольковой артерии и разными этапами развития гломерулосклероза (утолщение стенок капилляров клубочка, сращение и облитерация капиллярных петель, формирование фиброзно-клеточных полулуний)[40]. Установлено, что фиброз стенки междольковой артерии повышает вероятность развития гломерулосклероза[40]. Более того, показано, что ремоделирование артерий почек малого диаметра происходит по эвтрофному типу, т.е. с уменьшением внутреннего просвета.

B работах TracyRЕтакже показано, что на фоне структурной перестройки артерий малого диаметра (менее 0,3 мм в диаметре) при незначительно повышенном или нормальном уровне системного артериального давления происходит увеличение сосудистого сопротивления, с дальнейшим ремоделированием ткани почек [41].

Hanamura Ketal. показали высокую значимость артерий малого диаметра в прогрессировании патогенеза гломерулярного повреждения. Авторы продемонстрировали, что изменение структуры артериального сосудистого русла почек приводит к снижению перфузии клубочка, независимо от тяжести гломерулярного поражения[42].

Интересно отметить существующие данные, свидетельствующие о том, что почечная паренхима при микрососудистой перестройке повреждается по механизму «дефектногоангиогенеза» [43]. Суть данного патологического процесса основана на том, что при возникновении воспаления в артериях малого диаметра происходит неоангиогенез, со структурной неполноценностью вновь образованных сосудов. Воспалительные медиаторы, формирующиеся при неоангиогенезе, проникают в паренхиму почек, отягощающие патологический процесс.

Выводы.Основываясь на многочисленных научно-исследовательских работах можно утверждать, что процессы, происходящие при развитии и прогрессировании фиброза почек механизм многогранный, с вовлечением большого количества патогенетических механизмов местного и системного уровней. Выявление новых маркеров фиброза почек является актуальным в современной научной и практической деятельности. Своевременная и полноценная диагностика позволит дополнить существующие системы стратификации риска развития терминальной хронической почечной недостаточности.

Финансирование. Авторы заявляют об отсутствии конбликта интересов.

Конфликт интересов. Исследование не имело спонсорской поддержки.

\section{ЛИТЕРАТУРА}

1. Neovius M., Jacobson S.H., Eriksson J.K., Elinder C.G., Hylander B. Mortality in chronic kidney disease and renal replacement therapy: a population-based cohort study. // BMJ Open - 2014. V.4. - P.e00425. doi: 10.1136/bmjopen-2013-004251

2. Liu Y. Cellular and molecular mechanisms of renal fibrosis. // Nat Rev Nephrol. - 2011. - Vol.7(12). - P.684-696. doi: 10.1038/ nrneph.2011.149

3. Farris A.B., Colvin R.B. Renal Interstitial Fibrosis: Mechanisms and Evaluation In: Current Opinion in Nephrology and Hypertension. // CurrOpinNephrolHypertens. - 2012. Vol.21(3). - P.289-300. doi: 10.1097/MNH.0b013e3283521cfa

4. Zeisberg M., Neilson E.G. Mechanisms of tubulointerstitial fibrosis. // Journal of the American Society of Nephrology: JASN. - 2010. - Vol.21(11). - P.1819-1834. doi: 10.1681/ ASN.2010080793

5. Duffield J.S. Cellular and molecular mechanisms in kidney fibrosis. // J Clin Invest. - 2014. - Vol.124(6). - P.2299-2306. doi: 10.1172/JCI72267

6. Genoves F., Manresa A.A., Leeming D.J., Karsdal M.A., Boor P. The extracellular matrix in the kidney: a source of novel noninvasive biomarkers of kidney fibrosis? // Fibrogenesise Tissue Repair. - 2014. - Vol.7(1). - P.4. doi: 10.1186/1755-1536-7-4

7. Савош В.В., Летковская Т.А., Черствый Е.Д., Сукало А.В. Клеточные механизмы формирования тубулоинтерстициальных изменений при первичных гломерулопатиях. // Meдицинский журнал. - 2007. - №4. - С. 98-100.

8. Papasotiriou M., Genovese F., Klinkhammer B.M., Kunter U., Nielsen S.H., Karsdal M.A. et al. Serum and urine markers of collagen degradation reflect renal fibrosis in experimental kidney diseases. // Nephrol Dial Transplant. - 2015. - Vol.30(7). P.1112-1121. doi: 10.1093/ndt/gfv063

9. Dussaule J.C., Guerrot D., Huby A.C., Chadjichristos C., Shweke N., Boffa J.J. et al. The role of cell plasticity in progression and reversal of renal fibrosis. // Int J ExpPathol. - 2011. - Vol.92(3). -
P.151-7. doi: 10.1111/j.1365-2613.2011.00760.x

10. Boor P., Ostendorf T., Floege J. Renal fibrosis: novel insights into mechanisms and therapeutic targets. // Nat Rev Nephrol. - 2010. Vol.6(11). - P.643-56. doi: 10.1038/nrneph.2010.120

11. Tapmeier T.T., Fearn A., Brown K., Chowdhury P., Sacks S.H., Sheerin N.S. et al. Pivotal role of CD4+ T cells in renal fibrosis following ureteric obstruction. // Kidney international. - 2010. Vol.78(4). - P.351-362. doi: 10.1038/ki.2010.177

12. Khan F., Sar A., Gonul I., Benediktsson H., Doulla J., Yilmaz S. et al. Graft inflammation and histologic indicators of kidney chronic allograft failure: low-expressing interleukin-10 genotypes cannot be ignored. // Transplantation. - 2010. - Vol.90(6). - P.630-638. doi: 10.1097/TP.0b013e3181ea391e

13. Semedo P., Donizetti-Oliveira C., Burgos-Silva M., Cenedeze M.A., Avancini Costa Malheiros D.M., Pacheco-Silva A. et al. Bone marrow mononuclear cells attenuate fibrosis development after severe acute kidney injury. // Lab Invest. - 2010. - Vol.90(5). P.685-95. doi: 10.1038/labinvest.2010.45

14. Kitching A.R. Dendritic cells in progressive renal disease: some answers, many questions. // Nephrol Dial Transplant. - 2014. Vol.29(12). - P.2185-2193. doi: 10.1093/ndt/gfu076

15. Snelgrove S.L., Kausman J.Y., Lo C., Lo C., Ooi J.D., Coates P.T. et al. Renal dendritic cells adopt a pro-inflammatory phenotype in obstructive uropathy to activate $\mathrm{T}$ cells but do not directly contribute to fibrosis. // Am J Pathol. - 2012. - Vol.180(1). - P.91103. doi: 10.1016/j.ajpath.2011.09.039

16. Baba A., Tachi M., Ejima Y., Endo Y., Toyama H., Saito K. et al. Less contribution of mast cells to the progression of renal fibrosis in Rat kidneys with chronic renal failure. // NEPHROLOGY. 2017. - Vol.22(2). - P.159-167. doi: 10.1111/nep.12733

17. Zhao J., Wang L., Cao A., Jiang M., Chen X., Peng W. Renal Tubulointerstitial Fibrosis: A Review in Animal Models. // Journal of Integrative Nephrology \&Andrology. - 2015. - Vol.2(3). P.75-80. doi: 10.4103/2225-1243.161428 
18. López-Novoa J.M., Rodríguez-Peña A.B., Ortiz A., Martínez-Salgado C., López Hernández F.J. Etiopathology of chronic tubular, glomerular and renovascular nephropathies: Clinical implications. // Journal of Translational Medicine . - 2011. _ Vol.9. - P.13. doi: 10.1186/1479-5876-9-13

19. López-Marín L., Chávez Y., García X.A., Flores W.M., García Y.M., Herrera R. et al. Histopathology of Chronic Kidney Disease of Unknown Etiology in Salvadoran Agricultural Communities. // MEDICCReview. - 2014. - Vol.16(2). - P.49-54.

20. Батюшин M.M. Сулодексид. Нефропротективные свойства и горизонты применения в нефрологии. // Медицинский совет. - 2015. - №7. - С. 68-71. doi: 10.21518/2079-701X-20157-68-71

21. Tanaka Y., Kume S., Araki S., Isshiki K., Chin-Kanasaki M., Sakaguchi M. et al. Fenofibrate, a PPAR $\alpha$ agonist, has renoprotective effects in mice by enhancing renal lipolysis. // Kidney Int. - 2011. Vol.79(8). - P.871-82. doi: 10.1038/ki.2010.530

22. Cho K.H., Kim H.J., Kamanna V.S., Vaziri N.D. Niacin improves renal lipid metabolism and slows progression in chronic kidney disease. // BiochimBiophysActa. - 2010. - Vol.1800(1). - P.6-15. doi: 10.1016/j.bbagen.2009.10.009

23. Ortiz A., Ucero A.C., Egido J. Unravelling fibrosis: two newcomers and an old foe. // Nephrol Dial Transplant. - 2010. - Vol.25(11). P.3492-5. doi: 10.1093/ndt/gfq518

24. Wang Q., Usinger W., Nichols B., Gray J., Xu L., Seeley T.W. et al. Cooperative interaction of CTGF and TGF- $\beta$ in animal models of fibrotic disease. // Fibrogenesis Tissue Repair. - 2011. - Vol.4(1). P.4. doi: 10.1186/1755-1536-4-4

25. Loeffler I., Wolf G. Transforming growth factor- $\beta$ and the progression of renal disease. // Nephrol. Dial. Transplant. - 2014. Suppl.1. - P.i37-i45. doi: 10.1093/ndt/gft267

26. Pohlers D., Brenmoehl J., Löffler I., Müller C.K., Leipner C., Schultze-Mosgau S. et al. TGF-beta and fibrosis in different organs - molecular pathway imprints. // BiochimBiophysActa. 2009. - Vol.1792(8). - P.746-56. doi: 10.1016/j.bbadis.2009.06.004

27. Lee H.S. Mechanisms and consequences of TGF- $\beta$ overexpression by podocytes in progressive podocyte disease. // Cell Tissue Res. - 2012. - Vol.347(1). - P.129-40. doi: 10.1007/s00441-0111169-7

28. Ronco C. Cardiorenal syndromes: definition and classification // ContribNephrol. - 2010. - Vol.164. - P.33-38. doi: $10.1159 / 000313718$

29. Leask A. Targeting the jagged/notch pathway: a new treatment for fibrosis? // J Cell Commun Signal. - 2010. - Vol.4(4). - P.197-8. doi: 10.1007/s12079-010-0101-3

30. Sharma S., Sirin Y., Susztak K. The story of Notch and chronic kidney disease. // CurrOpinNephrolHypertens. - 2011. - Vol.20(1). P.56-61. doi: 10.1097/MNH.0b013e3283414c88
31. Maezawa Y., Takemoto M., Yokote K. Cell biology of diabetic nephropathy: Roles of endothelial cells, tubulointerstitial cells and podocytes. // J Diabetes Investig. - 2015. - Vol. 6(1). - P.3-15. doi: 10.1111/jdi.12255

32. Sato C., Zhao G., Ilagan M.X. An Overview of Notch Signaling in Adult Tissue Renewal and Maintenance. // Curr Alzheimer Res. 2012. - Vol.9(2). - P.227-240.

33. Ables J.L., Breunig J.J., Eisch A.J., Rakic P. Not(ch) just development: Notch signalling in the adult brain. // Nat Rev Neurosci. 2011. - Vol.12(5). - P.269-283. doi: 10.1038/nrn3024

34. Sirin Y., Susztak K. Notch in the kidney: development and disease. // J Pathol. - 2012. - Vol.226(2). - P.394-403. doi: 10.1002/ path.2967

35. Niranjan T., Bielesz B., Gruenwald A., Ponda M.P., Kopp J.B., Thomas D.B. et al. The Notch pathway in podocytes plays a role in the development of glomerular disease. // Nat Med. - 2008. Vol.14(3). - P.290-8. doi: 10.1038/nm1731

36. Xu Y., Xue S., Zhou J., Voorhees J.J., Fisher G.J. Notch and TGF- $\beta$ pathways cooperatively regulate receptor protein tyrosine phosphatase- $\kappa$ (PTPRK) gene expression in human primary keratinocytes. // MolBiolCell. - 2015. - Vol26(6). - P.1199-1206. doi: $10.1091 / \mathrm{mbc} . \mathrm{E} 14-12-1591$

37. Батюшин М.М., Гадаборшева Х.З. Белок сосудистой адгезии-1 (VAP-1) и его роль в моделировании воспалительного процесса и фиброза. Нефрологический вектор. //Неффрология. - 2015. - №5. - С. 23-27.

38. Jen K.Y., Haragsim L., Laszik Z.G. Kidney microvasculature in health and disease. // ContribNephrol. - 2011. - Vol.169. - P.5172. doi: 10.1159/000313945

39. Левицкая Е.С., Батюшин М.М., Пасечник Д.Г., Асрумян Э.Г. Ремоделирование почечных артерий - инициатор и мишень кардио-ренального континуума. // Кардиоваскулярная терапия и профилактика. - 2015. - Т. 4. - №1. - С. 90-96. doi: 10.15829/1728-8800-2015-1-90-96

40. Левицкая Е.С., Батюшин М.М, Пасечник Д.Г., Антипова Н.В. Прогнозирование ремоделирования ткани почек с учетом структурных изменений почечных артерий малого диаметра. // Нефрология. - 2016. - Т. 20. - №5. - С. 55-61.

41. Tracy R.E. Renal Vasculature in Essential Hypertension: A Review of Some Contrarian Evidence. // ContribNephrol. - 2011. Vol.169. - P.327-336. doi: 10.1159/000314908

42. Hanamura K., Tojo A., Kinugasa S., Asaba K., Fujita T. The Resistive Index Is a Marker of Renal Function, Pathology, Prognosis, and Responsiveness to Steroid Therapy in Chronic Kidney Disease Patients. // International Journal of Nephrology. - 2012. Vol.2012. - 9 p. doi: 10.1155/2012/139565

43. Eirin A., Lerman L.O. Darkness at the End of the Tunnel: Poststenotic Kidney Injury. // Physiology (Bethesda). - 2013. - Vol.28(4). P.245-253. doi: 10.1152/physiol.00010.2013

\section{REFERENCES}

1. Neovius M, Jacobson SH, Eriksson JK, Elinder CG, Hylander B. Mortality in chronic kidney disease and renal replacement therapy: a population-based cohort study. BMJ Open 2014;4:e00425. doi: 10.1136/bmjopen-2013-004251

2. Liu Y. Cellular and molecular mechanisms of renal fibrosis. Nat Rev Nephrol. 2011;7(12):684-696. doi: 10.1038/nrneph.2011.149

3. Farris AB, Colvin RB. Renal Interstitial Fibrosis: Mechanisms and Evaluation In: Current Opinion in Nephrology and Hypertension. CurrOpinNephrolHypertens. 2012;21(3):289-300. doi: 10.1097/ MNH.0b013e3283521cfa

4. Zeisberg M, Neilson EG. Mechanisms of tubulointerstitial fibrosis. Journal of the American Society of Nephrology: JASN. 2010;21(11):1819-1834. doi: 10.1681/ASN.2010080793

5. Duffield JS. Cellular and molecular mechanisms in kidney fibrosis. J Clin Invest. 2014;124(6):2299-2306. doi: 10.1172/JCI72267

6. Genoves F, ManresaAA, LeemingDJ, Karsdal MA, BoorP. The extracellular matrix in the kidney: a source of novel non-invasive biomarkers of kidney fibrosis? Fibrogenesis\& Tissue Repair. 2014;7(1):4. doi: 10.1186/1755-1536-7-4

7. Savosh VV, Letkovskaja TA, Cherstvyj ED, Sukalo AV. Cellular mechanisms of tubulointerstitial changes in primary glomerulopathy. Medical Journal. 2007;4:98-100. (In Russ).

8. Papasotiriou M, Genovese F, Klinkhammer BM, Kunter U, Nielsen SH, Karsdal MA et al. Serum and urine markers of collagen degradation reflect renal fibrosis in experimental kidney diseases. Nephrol Dial Transplant. 2015;30(7):1112-1121. doi: 10.1093/ndt/gfv063

9. Dussaule JC, Guerrot D, Huby AC, Chadjichristos C, Shweke $\mathrm{N}$, Boffa JJ et al. The role of cell plasticity in progression and reversal of renal fibrosis. Int J ExpPathol. 2011;92(3):151-7. doi: 10.1111/j.1365-2613.2011.00760.x

10. Boor P, Ostendorf T, Floege J. Renal fibrosis: novel insights into mechanisms and therapeutic targets. Nat Rev Nephrol. 2010;6(11):643-56. doi: 10.1038/nrneph.2010.120 
11. Tapmeier TT, Fearn A, Brown K, Chowdhury P, Sacks SH, Sheerin NS et al. Pivotal role of CD4+ T cells in renal fibrosis following ureteric obstruction. Kidney international. 2010;78(4):351-362. doi: 10.1038/ki.2010.177

12. Khan F, Sar A, Gonul I, Benediktsson H, Doulla J, Yilmaz S et al. Graft inflammation and histologic indicators of kidney chronic allograft failure: low-expressing interleukin-10 genotypes cannot be ignored. Transplantation. 2010;90(6):630-638. doi: 10.1097/ TP.0b013e3181ea391e

13. Semedo P, Donizetti-Oliveira C, Burgos-Silva M, Cenedeze MA, Avancini Costa Malheiros DM, Pacheco-Silva A et al. Bone marrow mononuclear cells attenuate fibrosis development after severe acute kidney injury. Lab Invest. 2010;90(5):685-95. doi: 10.1038/ labinvest.2010.45

14. Kitching AR. Dendritic cells in progressive renal disease: some answers, many questions. Nephrol Dial Transplant. 2014;29(12):2185-2193. doi: 10.1093/ndt/gfu076

15. Snelgrove SL, Kausman JY, Lo C, Lo C, Ooi JD, Coates PT et al. Renal dendritic cells adopt a pro-inflammatory phenotype in obstructive uropathy to activate T cells but do not directly contribute to fibrosis. Am J Pathol. 2012;180(1):91-103. doi: 10.1016/j. ajpath.2011.09.039

16. Baba A, Tachi M, Ejima Y, Endo Y, Toyama H, Saito K et al. Less contribution of mast cells to the progression of renal fibrosis in Rat kidneys with chronic renal failure. NEPHROLOGY. 2017;22(2):159-167. doi:10.1111/nep.12733

17. Zhao J, WangL, Cao A, Jiang M, Chen X, Peng W. Renal Tubulointerstitial Fibrosis: A Review in Animal Models. Journal of Integrative Nephrology \&Andrology. 2015;2(3):75-80. doi: 10.4103/22251243.161428

18. López-Novoa JM, Rodríguez-Peña AB, Ortiz A, Martínez-Salgado C, LópezHernández FJ. Etiopathology of chronic tubular, glomerular and renovascular nephropathies: Clinical implications. JTranslMed. 2011;9:13. doi: 10.1186/1479-5876-9-13

19. López-Marín L, Chávez Y, García XA, Flores WM, GarcíaYM, Herrera R et al. Histopathology of Chronic Kidney Disease of Unknown Etiology in Salvadoran Agricultural Communities. MEDICC Review. 2014;16(2):49-54.

20. Batyushin MM. Sulodexide. Nephroprotective properties and horizons for use in nephrology. Medical Council. 2015;(7):68-71. (In Russ.) doi:10.21518/2079-701X-2015-7-68-71

21. Tanaka Y, Kume S, Araki S, Isshiki K, Chin-Kanasaki M, Sakaguchi $\mathrm{M}$ et al. Fenofibrate, a PPARa agonist, has renoprotective effects in mice by enhancing renal lipolysis. Kidney Int. 2011;79(8):871-82. doi: 10.1038/ki.2010.530

22. Cho KH, Kim HJ, Kamanna VS, Vaziri ND. Niacin improves renal lipid metabolism and slows progression in chronic kidney disease. BiochimBiophysActa. 2010;1800(1):6-15. doi: 10.1016/j. bbagen.2009.10.009

23. Ortiz A, Ucero AC, Egido J. Unravelling fibrosis: two newcomers and an old foe. Nephrol Dial Transplant. 2010;25(11):3492-5. doi: $10.1093 / \mathrm{ndt} / \mathrm{gfq} 518$

24. Wang Q, Usinger W, Nichols B, Gray J, Xu L, Seeley TW et al. Cooperative interaction of CTGF and TGF- $\beta$ in animal models of fibrotic disease. Fibrogenesis Tissue Repair. 2011;4(1):4. doi: $10.1186 / 1755-1536-4-4$

25. Loeffler I, Wolf G. Transforming growth factor- $\beta$ and the progression of renal disease. Nephrol. Dial. Transplant. 2014;(1):i37-i45. doi: $10.1093 / \mathrm{ndt} / \mathrm{gft} 267$

26. Pohlers D, Brenmoehl J, Löffler I, Müller CK, Leipner C, Schultze-
Mosgau S et al. TGF-beta and fibrosis in different organs- molecularpathway imprints. BiochimBiophysActa. 2009;1792(8):74656. doi: 10.1016/j.bbadis.2009.06.004.

27. Lee HS. Mechanisms and consequences of TGF- $ß$ overexpression by podocytes in progressive podocyte disease. Cell Tissue Res. 2012;347(1):129-40. doi: 10.1007/s00441-011-1169-7

28. Ronco C. Cardiorenal syndromes: definition and classification. ContribNephrol. 2010;164:33-38. doi: 10.1159/000313718

29. Leask A. Targeting the jagged/notch pathway: a new treatment for fibrosis? J Cell Commun Signal. 2010;4(4):197-8. doi: 10.1007/ s12079-010-0101-3

30. Sharma S, Sirin Y, Susztak K. The story of Notch and chronic kidney disease. CurrOpinNephrolHypertens. 2011;20(1):56-61. doi: 10.1097/MNH.0b013e3283414c88

31. Maezawa Y, Takemoto M, Yokote K. Cell biology of diabetic nephropathy: Roles of endothelial cells, tubulointerstitial cells and podocytes. J Diabetes Investig. 2015;6(1):3-15. doi: 10.1111/ jdi. 12255

32. Sato C, Zhao G, Ilagan MX. An Overview of Notch Signaling in Adult Tissue Renewal and Maintenance. CurrAlzheimerRes. 2012;9(2):227-240.

33. Ables JL., Breunig JJ, Eisch AJ, Rakic P. Not(ch) just development: Notch signalling in the adult brain. Nat Rev Neurosci. 2011;12(5):269-283. doi: 10.1038/nrn3024

34. Sirin Y, Susztak K. Notch in the kidney: development and disease. J Pathol. 2012;226(2):394-403. doi: 10.1002/path.2967

35. Niranjan T, Bielesz B, Gruenwald A, Ponda MP, Kopp JB, Thomas $\mathrm{DB}$ et al. The Notch pathway in podocytes plays a role in the development of glomerular disease. Nat Med. 2008;14(3):290-8. doi: $10.1038 / \mathrm{nm} 1731$

36. Xu Y, Xue S, Zhou J, Voorhees JJ, Fisher GJ. Notch and TGF- $\beta$ pathways cooperatively regulate receptor protein tyrosine phosphatase- $\kappa$ (PTPRK) gene expression in human primary keratinocytes. MolBiol Cell. 2015;26(6):1199-1206. doi: 10.1091/ mbc.E14-12-1591

37. Batiushin MM, Gadaborsheva HZ. Vascular adhesion protein-1 (VAP-1) and its role in modeling inflammation and fibrosis. Nephrology vector. Nephrology. 2015;5:23-27. (In Russ).

38. Jen KY, Haragsim L, Laszik ZG. Kidney microvasculature in health and disease. ContribNephrol. 2011;169:51-72. doi: $10.1159 / 000313945$

39. Levitskaya ES, Batiushin MM, Pasechnik DG, Asrumjan JeG. Remodeling of the renal arteries - the initiator and target cardio-renal continuum. Cardiovascular therapy and prevention. 2015;4(1): 0-96. (In Russ). doi: 10.15829/1728-8800-2015-1-90-96

40. Levitskaya ES, Batiushin MM, Pasechnik DG, Antipova NV. Predicting renal tissue remodeling based on structural changes of the renal arteries of small diameter. Nephrology. 2016;20(5):55-61.(In Russ).

41. Tracy RE. Renal Vasculature in Essential Hypertension: A Review of Some Contrarian Evidence. ContribNephrol. 2011;169:327336. doi: $10.1159 / 000314908$

42. Hanamura K, Tojo A, Kinugasa S, Asaba K, Fujita T. The Resistive Index Is a Marker of Renal Function, Pathology, Prognosis, and Responsiveness to Steroid Therapy in Chronic Kidney Disease Patients. International Journal of Nephrology. 2012;2012:139565. doi: 10.1155/2012/139565

43. Eirin A, Lerman LO. Darkness at the End of the Tunnel: Poststenotic Kidney Injury. Physiology (Bethesda). 2013;28(4):245-253. doi: $10.1152 /$ physiol.00010.2013 